\title{
13. Design science in IS research: a literature analysis
}

\author{
MARTA INDULSKA \\ UNIVERSITY OF QUEENSLAND
}

\author{
JAN RECKER \\ QUEENSLAND UNIVERSITY OF TECHNOLOGY
}

\section{Abstract}

The publication of the work on design science by Alan Hevner and his colleagues has fostered much discussion on what is and what is not considered to be design science in information systems (IS) research. Anecdotal evidence suggests that some authors claim design science as a methodology in their work, without much consideration of theoretical or methodological aspects or the appropriateness of their artefact. Also, it would appear that designscience papers have been proliferating rapidly of late. Accordingly, we were interested to identify the proliferation, nature and quality of design-science research in IS conference publications since the publication of Hevner et al.'s work in 2004. We examine design-science articles published at five major IS conferences in the past three years. We subject 83 articles-identified as relevant via a rigorous analysis process - to three types of analysis: statistical, thematic and methodological. The results of these analyses indicate that design science appears to be a growing stream of research in IS. We also found designscience research to be strongly prevalent in the research domains of process, knowledge and information management. The most interesting results stem from our methodological analysis, which suggests that only a small percentage of the papers discuss a concise and consistent implementation of the designscience methodology suggested by Hevner et al. 


\section{Introduction}

Recent years have seen an increased interest in topics associated with design science or design research within the information systems (IS) community. Most of this interest emerged after the publication of Hevner et al.'s (2004) paper on design science. Since then, some the most prestigious IS journals have launched special issues on design science. These include the Journal of Information Technology Theory and Application (JITTA) in 2004, the Journal of the Association of Information Systems (JAIS) in 2007 and, most recently, MIS Quarterly (MISQ), in 2008. Some of the most prominent IS conferences - for example, the Americas Conference on Information Systems (AMCIS) and the International Conference on Information Systems (ICIS) - also now feature tracks dedicated to design-science research. New conferences on design science in IS, such as the International Conference on Design Science in Information Systems and Technology (DESRIST), have likewise been introduced in the past few years. Last, but not least, the online forum ISWorld now features a web page on design science. The dedicated page includes details of the design-science methodology and a list of other related resources (for example, publication outlets) (<http:// www.isworld.org/Researchdesign/drisISworld.htm $>$ ). All of these efforts show an increasing interest in design science within the IS research community.

The main motivation behind the emergence of design science as a research paradigm in IS was to complement the 'mainstream' behavioural orientation of IS research with more design-oriented science research (Hevner et al. 2004; March and Smith 1995; Walls et al. 1992). This move sought to address lack of relevance in the field of IS (Applegate and King 1999; Benbasat and Zmud 1999; Rosemann and Vessey 2008).

Clearly, the emerging discussion about design aspects in IS should be seen as encouraging. In the end, IS research is concerned with the design, development, implementation and use of socio-technical systems in organisational contexts (Zmud and Boynton 1991). With the emergence of design science, however, and its surrounding discussions, a number of questions and issues surface. Some researchers argue a lack of defined scope and boundaries for the design-science approach in IS (for example, Carlsson 2005b). Others are concerned about the unclear philosophical presuppositions of design science (for example, Niehaves 2007). More generally, a wide range of scholars lament a lack of clarity in the understandings of, and endeavours in, design science (for example, McKay and Marshall 2005). These, and similar, arguments often tap into the issue of the difference between high-quality professional design and design-science research (Gibson and Arnott 2007). 
While design science, or design theory, was discussed as early as 1992 (Walls et al. 1992), and further developed in the mid-1990s (March and Smith 1995) and the new millennium (Markus et al. 2002), it was the Hevner et al. (2004) publication that propelled design science out of its niche into the headlights of the IS community. In their paper, Hevner et al. (2004) argue that design science in IS attempts to create and evaluate IT artefacts intended to solve identified relevant organisational problems. They go on to suggest seven guidelines for the conduct, evaluation and communication of design-science research in IS.

Notwithstanding earlier or other contributions to design-oriented research in IS (for example, March and Smith 1995; Markus et al. 2002; Walls et al. 1992), the motivation of this chapter is to study the progress of design-science research in IS in the years that have followed the publication by Hevner et al. (2004). To this end, we carry out a literature analysis of work published at five prominent academic IS conferences in 2005, 2006 and 2007. The conferences considered include: Australasian Conference on Information Systems (ACIS), Americas Conference on Information Systems (AMCIS), European Conference on Information Systems (ECIS), International Conference on Information Systems (ICIS) and Pacific-Asia Conference on Information Systems (PACIS). In our literature analysis, we focus on relevant design-science papers within these conferences and we wish to address the following questions.

- What proportion of papers at IS conferences pertains to design-science research?

- Is the focus on design science in IS publication outlets increasing in recent years?

- What are the main thematic foci of IS design-science papers?

- Is design science in IS concentrated within schools in specific geographical areas?

- To what extent do design-science papers discuss the seven guidelines specified by Hevner et al. (2004) and how are these guidelines implemented?

We proceed as follows. Section two presents the methodology we employed to ensure a rigorous and unbiased analysis process. The descriptive statistics from our publication analysis are presented in section three. In section four, we review the extent to which published design-science work discusses and implements design-science methodologies, following the seven guidelines suggested by Hevner et al. (2004). Section five discusses our thematic analysis of the papers, aided by the use of the Leximancer analysis tool. We conclude in section six with a discussion of our findings and some recommendations for the road ahead. 


\section{Methodology}

As a first step, we took as our data set the collection of papers published at the five main AIS-sponsored IS conferences - namely, ACIS, AMCIS, ECIS, ICIS and PACIS. We considered papers in the years 2005-07 (that is, papers that followed the publication of the design-science paper by Hevner et al. [2004]). With this specific focus, we do not wish to discredit other work on design science in IS but rather seek to enable meaningful and focused analysis in our study. We specifically focus on conferences as publication outlets, as opposed to journals, due to the relatively short period from idea conception to publication. The conference paper data set consists of 3284 papers, which was prepared and indexed for a full text search.

From the 3284 papers, we extracted 94 papers that matched the search term of 'Hevner' and a further 129 papers that matched the search term of 'design science' in a full text search. After eliminating duplicate papers from the search results, the final data set for the subsequent analysis consisted of 142 papers. Two researchers carried out the searches and identification of duplicate papers independently. The researchers then met to consolidate the result sets, with no identified inconsistencies.

The search terms restrict the set of papers to those that either directly follow the Hevner et al. study or refer to design science. While this choice limits the scope of our study, it also enables a focused analysis. Other search terms (for example, 'design theory') can also be used and could potentially yield different results. Those terms (for example, 'design theory') did not, however, always imply that a design-science methodology was followed, which was why we opted not to include this search term.

The set of 142 selected papers was subjected to a categorisation of design-science contribution into four categories, viz.- methodology, discussion, application and other.

- Methodology: Papers that discussed the conduct of design science in specific IS research domains, such as systems analysis and design (Tan et al. 2007), or that discussed the combination or role of the design-science methodology with other approaches to IS, such as focus groups (Gibson and Arnott 2007) or action research (Purao et al. 2005). Three such papers were identified from the set of 142 publications.

- Discussion: Papers that discussed the design-science approach from a variety of angles, including its epistemological presuppositions (Niehaves 2007), its previous applications in IS (McKay and Marshall 2005), its combination with paradigms such as critical realism (Carlsson 2005a) and others. Fourteen such papers were identified. 
- Application: Papers that reported on the implementation of the design-science approach in their respective domains of study. Fifty-seven such papers were identified.

- Other: This cluster contains another nine papers, of which seven feature only a brief mention of design science, and two refer to design science in their outlook to future work.

At this stage of the analysis, we identified a number of papers (59 in total) that had to be eliminated from the analysis due to lack of relevance to the theme 'design science'. A variety of reasons for exclusion were encountered

- a paper was published in a 'design-science' track but did not in fact cover design science in the understanding relevant to this chapter

- a paper referred to, or referenced, 'design science' without making a contribution to design science itself

- a paper used the classification of artefacts suggested by Hevner et al. (2004) for a study other than design science

- a paper was a panel discussion.

Two researchers independently performed the analysis of paper relevance and then met to revise their classification. Four inconsistencies ( 3 per cent) were found and were resolved before further analysis was carried out. This stage of the analysis narrowed the data set down to 83 design-science papers.

The next stage of the analysis process involved classification of papers that belonged to the 'application' category. The main aim of this stage was to gain an insight into the extent of design-science contribution within those papers. More specifically, we were interested in whether, and to what extent, published design-science papers followed the seven methodological guidelines suggested by Hevner et al. (2004). The categories emerged during the first round of analysis and were refined by the two researchers before the second round of analysis was carried out. The final set of categories used was as follows: 'merely states that it follows design-science guidelines', 'focuses on one guideline', 'focuses on some but not all guidelines', 'focuses on all guidelines without elaborating on their implementation', 'elaborates on the implementation of all guidelines', 'merely states that it belongs to design-science research' and 'states that it uses design science in combination with other methodologies'. A further discussion of these classifications is provided in section four.

The final stage of the data analysis was concerned with the identification of themes in the set of relevant papers. To this end, we used a data-mining tool, Leximancer, in order to generate automatically themes from the data. The details of the analysis are presented in section five. 


\section{Publication analysis}

The analysis and categorisation of publications identified 83 papers relevant to the analysis of design-science research. The results are summarised-per conference and per year-in Table 13.1. The table also shows the total number of papers over the three-year period for each conference, allowing the calculation of the ratio of papers focusing on design science.

Table 13.1 Design-science papers published in AIS conferences during 2005-07

\begin{tabular}{|l|l|l|l|l|l|l|}
\cline { 2 - 8 } \multicolumn{1}{c|}{} & ACIS & AMCIS & ECIS & ICIS & PACIS & Total \\
\hline 2005 & 4 & 4 & 3 & 2 & 0 & 13 \\
\hline 2006 & 4 & 13 & 3 & 7 & 1 & 28 \\
\hline 2007 & 6 & 17 & 13 & 4 & 2 & 42 \\
\hline Total & 14 & 34 & 19 & 13 & 3 & 83 \\
\hline $\begin{array}{l}\text { Total of all published papers, } \\
2005-07\end{array}$ & 336 & 1578 & 568 & 376 & 426 & 3284 \\
\hline DS papers to published papers & $4 \%$ & $2 \%$ & $3 \%$ & $3 \%$ & $1 \%$ & $3 \%$ \\
\hline
\end{tabular}

The results show that, while design-science research published at IS conferences still represents a very small percentage of the total number of papers published at such venues ( 3 per cent of all published papers), it is on the increase. Of 1037 papers published at the considered conferences in 2005, 13 were concerned with design science ( 1.3 per cent). This ratio increased to 2.5 per cent (28 of 1108 papers) in 2006 and 3.7 per cent (42 of 1139 papers) in 2007. A KruskalWallis one-way analysis of variance showed this increase to be significant at $\mathrm{p}=0.001$. This result indicates that, over recent years, significantly more designscience papers have been published at IS conferences (confirmed by a second ANOVA analysis).

Figure 13.1 shows the number of design-science publications at the five considered conferences per annum. ACIS and PACIS show a steady but slow increase in design-science papers. ECIS shows a significant increase of designscience papers in 2007 relative to its previous years. We can only speculate that this increase could be related to the conference's theme in that year ('Relevant Rigour-Rigorous Relevance'), the fact that the conference featured a panel discussion on design science or the fact that Alan Hevner was the keynote speaker. AMCIS and ICIS, on the other hand, featured dedicated design-science tracks in 2006 and 2007. Interestingly, however, we note a decrease in designscience papers in 2007 at ICIS while the share of design-science papers at AMCIS continues to increase. 


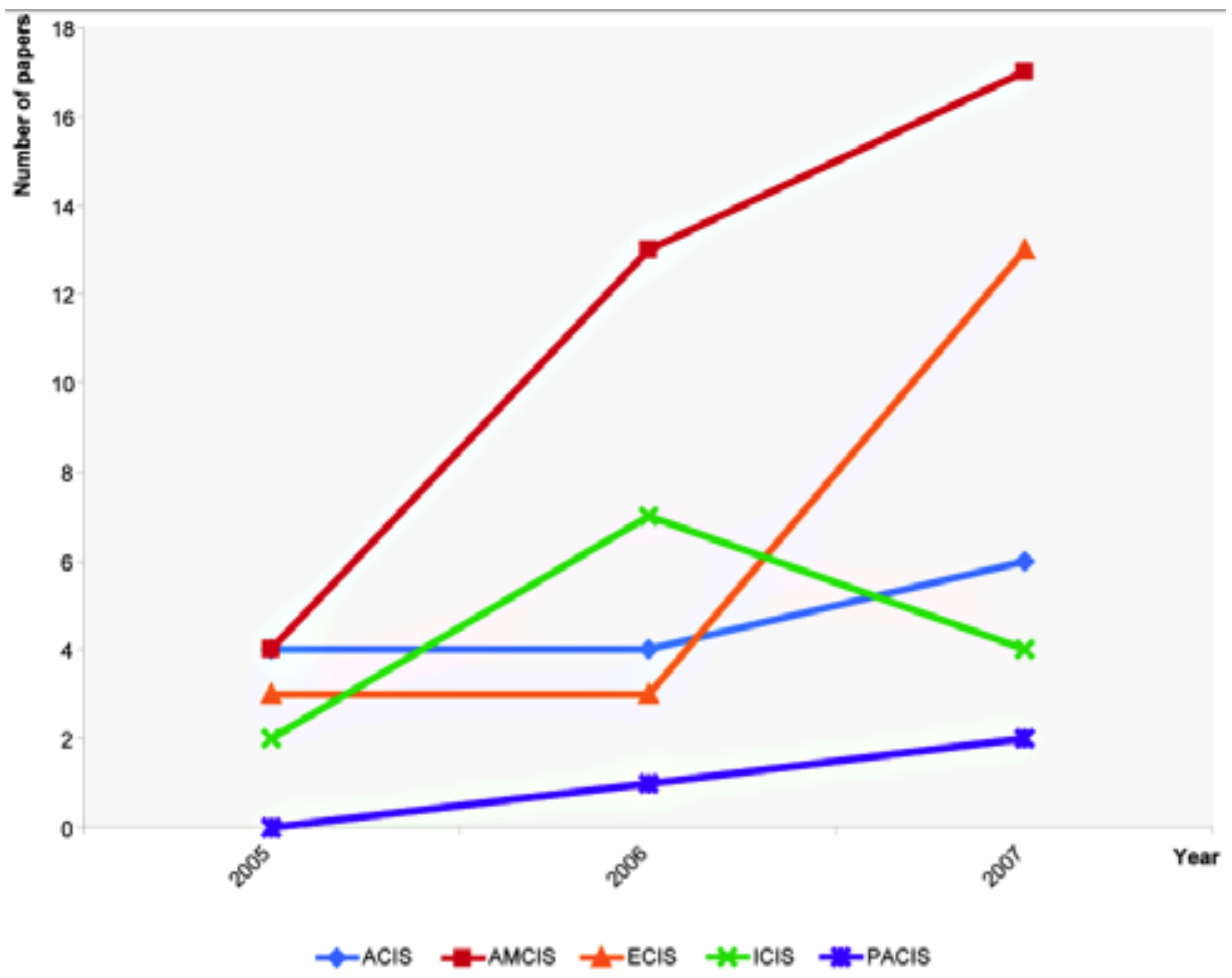

Figure 13.1 Longitudinal display of number of publications at AIS conferences per annum

In carrying out our analysis, we also recorded the country of origin of the first publishing author. From this data, Figure 13.2 shows the geographical distribution of publications. More than 39 per cent of publications originate from departments within the United States (39.76 per cent), closely followed by Europe (33.73 per cent). Authors from IS departments in the Asia/Pacific Rim (Australia, Hong Kong and New Zealand) are responsible for 19.28 per cent of design-science publications. Contrasted with other literature studies - most notably Lyytinen et al. (2007) — the geographical distribution of design-science researchers appears to deviate from the distribution of IS scholars publishing in high-impact journals. ${ }^{1}$

1 This statement has to be approached with caution. The Lyytinen et al. (2007) study concerns journal articles and the time frame of 2000-05, while our study concerns conference papers during 2005-07. 


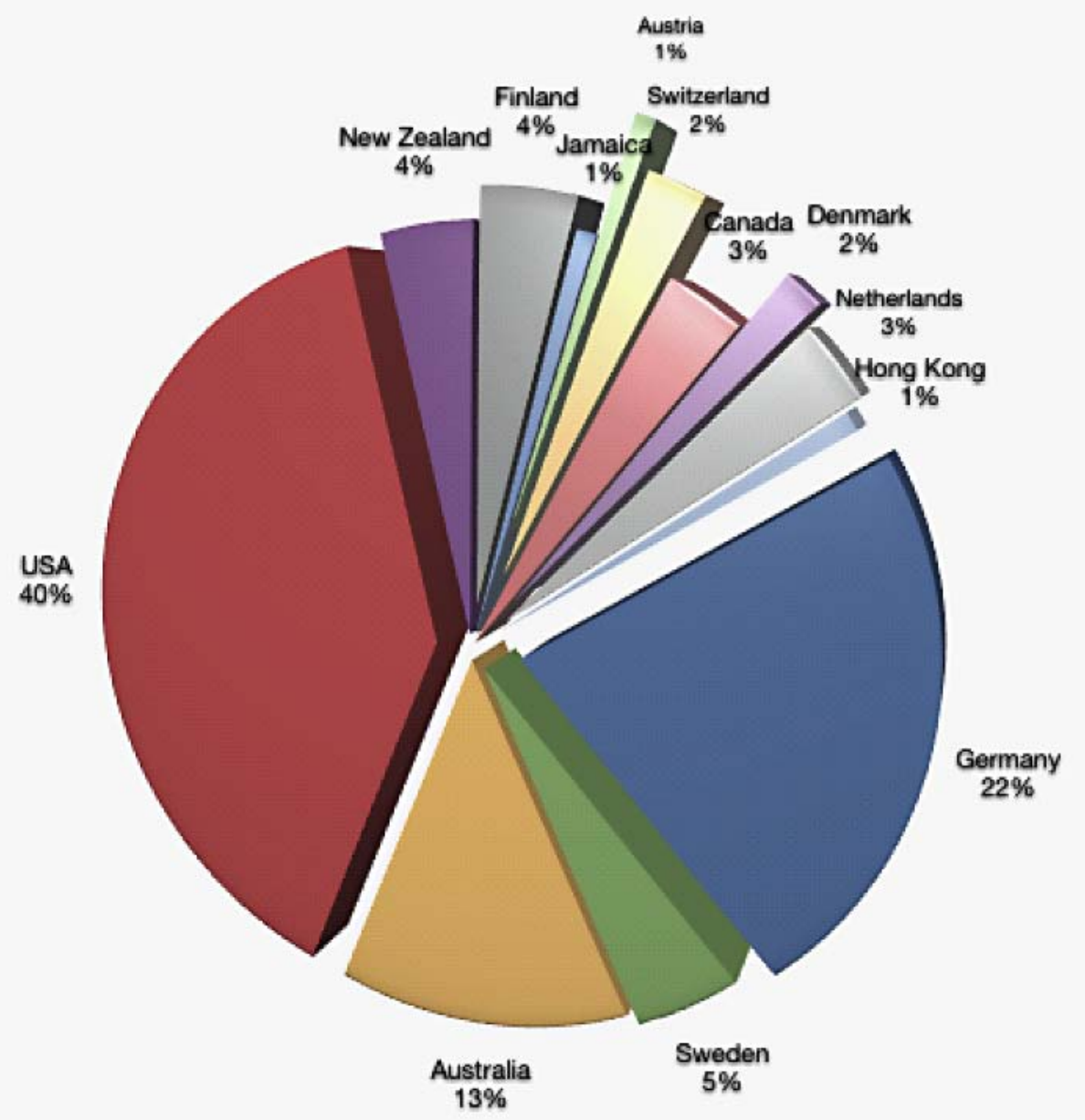

\section{Figure 13.2 First author's country of origin}

Based on the statement by Lyytinen et al. (2007) - that 25 per cent of all IS scholars work in European IS departments - we note an over-proportional share of design-science contributions from European IS scholars. This could be seen as evidence for the prevalent view that European IS scholars often view IS as an applied discipline with a strong focus on practical relevance and design constructions - the tool/method-first contribution (Lyytinen et al. 2007). Statements about Asia/Pacific Rim scholars are hard to make due to lack of statistics on the proportion of scholars in comparison with Europe or North America. We speculate, however, that the share of design-science contributions identified (19.28 per cent) is proportionally high. 


\section{Methodological analysis}

One of the continuing debates about design science in IS concerns the real procedure by which design-science research is executed (for example, McKay and Marshall 2005; Niehaves 2007). More precisely, McKay and Marshall (2005:7) lament that while Hevner et al. (2004) 'articulate some guidelines for design science research, stemming from its problem solving orientation, and then list some appropriate approaches for the evaluation of the designed artefact: they do not, in fact, propose a method or process for the conduct of design research'.

In light of these debates, we examined the set of papers in respect to whether, and how, IS scholars conducting design-science work implemented and executed the seven guidelines suggested by Hevner et al. (2004) and shown in Table 13.2. Through this analysis, we can identify: 1) whether or not design-science scholars follow the suggestions of Hevner et al. (2004); and 2) how they go about implementing the guidelines through appropriate research methods, tools or techniques. To that end, we scrutinised 57 papers that we identified as being 'application' papers and coded each of the papers using the seven classifications of guideline referral described in section two.

\section{Table 13.2 Design-science research guidelines}

\begin{tabular}{|l|l|}
\hline Guideline & \multicolumn{2}{l|}{ Description } \\
$\begin{array}{l}\text { Guideline 1: Design as an } \\
\text { artefact }\end{array}$ & $\begin{array}{l}\text { Design-science research must produce a viable artefact } \\
\text { in the form of a construct, a model, a method or an } \\
\text { instantiation. }\end{array}$ \\
\hline $\begin{array}{l}\text { Guideline 2: Problem } \\
\text { relevance }\end{array}$ & $\begin{array}{l}\text { The objective of design-science research is to develop } \\
\text { technology-based solutions to important and relevant } \\
\text { business problems. }\end{array}$ \\
\hline $\begin{array}{l}\text { Guideline 3: Design } \\
\text { evaluation }\end{array}$ & $\begin{array}{l}\text { The utility, quality and efficacy of a design artefact must } \\
\text { be rigorously demonstrated via well-executed evaluation } \\
\text { methods. }\end{array}$ \\
\hline $\begin{array}{l}\text { Guideline 4: Research } \\
\text { contributions }\end{array}$ & $\begin{array}{l}\text { Effective design-science research must provide clear and } \\
\text { verifiable contributions in the areas of the design artefact, } \\
\text { design foundations and/or design methodologies. }\end{array}$ \\
\hline Guideline 5: Research rigour & $\begin{array}{l}\text { Design-science research relies on the application of rigorous } \\
\text { methods in both the construction and the evaluation of the } \\
\text { design artefact. }\end{array}$ \\
\hline $\begin{array}{l}\text { Guideline 6: Design as a } \\
\text { search process }\end{array}$ & $\begin{array}{l}\text { The search for an effective artefact requires utilising } \\
\text { available means to reach desired ends while satisfying laws } \\
\text { in the problem environment. }\end{array}$ \\
\hline $\begin{array}{l}\text { Guideline 7: Communication } \\
\text { of research }\end{array}$ & $\begin{array}{l}\text { Design-science research must be presented effectively } \\
\text { to both technology-oriented and management-oriented } \\
\text { audiences. }\end{array}$ \\
\hline
\end{tabular}

Source: Hevner et al. (2004:83) 
Our analysis yields a number of interesting results. Table 13.3 shows the frequency count of papers we classified in the seven categories. We note that the largest share of papers (36.8 per cent) claims to follow the design-science guidelines without elaborating on how the seven guidelines apply to their work or how they implemented and/or executed the guidelines. Of these, some papers discuss some of the original guidelines - for instance, foundations, relevance, rigour or evaluation - without elaborating on their application in the research domain at hand, while others merely state 'the methodology used is essentially design science, though the proposed model still needs validation'.

\section{Table 13.3 Results from the methodological analysis}

\begin{tabular}{|l|l|}
\hline Coding category & $\begin{array}{l}\text { Number of papers } \\
\text { within category }\end{array}$ \\
\hline Merely states that it follows design-science guidelines & $21(36.8 \%)$ \\
\hline Focuses on one guideline & $13(22.8 \%)$ \\
\hline Focuses on some but not all guidelines & $4(7.0 \%)$ \\
\hline Focuses on all guidelines without elaborating on their implementation & $0(0.0 \%)$ \\
\hline Elaborates on the implementation of all guidelines & $11(19.3 \%)$ \\
\hline Merely states that it belongs to design-science research & $4(7.0 \%)$ \\
\hline States that it uses design science in combination with other methodologies & $4(7.0 \%)$ \\
\hline
\end{tabular}

An additional 7 per cent of papers claimed affiliation to design science through statements such as 'this paper can be classified as empirically founded design science' or 'it provides an apt illustration of design science in information systems research'.

Of the papers that focused more deeply on one, several or all of the guidelines (28 in total), 46.4 per cent (22.8 per cent of all papers) focused on one guideline. At times, this was due to the early stage of the research progress ('we are still in the "Generate design alternatives" phase of Simon's Generate/Test Cycle'). The one guideline most frequently mentioned in the 13 papers focusing on one guideline only was that of 'design evaluation' (nine referrals in total). Of the papers that focused on more than one guideline, we found that the guidelines of problem relevance, research rigour and design evaluation were mostly present.

Eleven papers elaborated in a comprehensive manner on their consideration of the seven guidelines - mostly in the form of a table that summarised the implementation of the guidelines (see, for instance, Klose et al. 2007; Knackstedt et al. 2007). Notably, the one guideline receiving the weakest attention was that of 'communication of research'. Interestingly, the six papers that were found to discuss the implementation of the seven guidelines well all originated from Germany. 
Of the papers that combined design science with other approaches to IS research (four papers in total), we found that grounded theory, experiments and action research were approaches of choice.

\section{Thematic analysis}

In a last step, we were interested in the types of content, subject area and/or topic discussed in design-science research articles. To that end, we subjected all identified papers to a thematic analysis procedure using the content analysis tool Leximancer. ${ }^{2}$

Leximancer allows users to analyse large amounts of text quickly. The tool performs a full text analysis both systematically and graphically by creating a map of the concepts and themes reappearing in the texts - a so-called document map. The concepts are displayed in such a manner that links to related subtext can subsequently be explored. Each of the identified concepts is placed on the map in proximity of other concepts in the map through a derived combination of the direct and indirect relationships between those concepts. Essentially, Leximancer employs a machine-learning technique based on the Bayesian approach to prediction. The procedure used for this is a self-ordering optimisation technique (unlike neural networks). Once the optimal weighted set of words is found for each concept, it is used to predict the concepts present in fragments of related text. In other words, each concept has other concepts that it attracts (or is highly associated with contextually) as well as concepts that it repels (or is highly disassociated with contextually). The relationships are measured by the weighted sum of the number of times two concepts are found in the same 'chunk'. An algorithm is used to weight them and determine the confidence and relevancy of the terms to others in a specific chunk and across chunks.

We used Leximancer as a qualitative data-analysis tool for several reasons

- its ability to derive the main concepts within text and their relative importance using a scientific, objective algorithm

- its ability to identify the centrality of concepts

- its ability to assist in applying grounded theory analysis to a textual data set

- its ability to assist in visually exploring textual information for related themes.

To prepare the data set for Leximancer analysis, we used the categorisation of the papers discussed earlier and created two main data sets: 1) application papers

2 For more information about the Leximancer tool, please refer to $<$ http://www.leximancer.com $>$ 
(57 in total); and 2) methodology and discussion papers (17 in total). These were created for each conference under consideration, with the exception of PACIS, at which no design-science methodology or discussion papers were published in the past three years.

Leximancer analysis was performed separately for each 'application' and 'methodology and discussion' set of papers at each of the five conferences. In each case, after one Leximancer pass, the list of automatically generated concepts was edited to remove the concept terms 'Hevner', 'March', 'Information_Systems' (which appears due to URL references in many of the papers) and 'Quarterly'. These concepts were removed because they did not add to the understanding of the content of the paper (given the already narrowed data set of papers) and would only clutter and dominate the generated theme map. The analyses uncovered subtle differences in design-science themes discussed at the various conferences. Due to lack of space, we omit these results here and present the overall thematic analysis findings.

Following the individual conference analyses, we ran separate Leximancer analyses of all methodology and discussion papers, all application papers and the overall set of papers. In these analyses, the additional concept of 'paper' was removed before running the analysis a second time, due to the frequency of the term across the whole data set.

The analysis of the methodology and discussion papers identifies a number of central themes, as shown in Figure 13.3. The strongest recurring theme is that of 'research', which includes the analysis of existing research and available data, and is closely related to analysis and evaluation of methods. Other strong themes in the paper set include those of 'design' and 'systems', which indicate a proportionately significant amount of discussion about the real design of artefacts and a discussion of the field of IS and related technical development. Overall, the concept map in Figure 13.3 indicates that the continuing debate on designscience research in IS focuses on themes such as its role in the IS discipline, the choice of appropriate research methods and theories in conjunction with design science, and the question of the underlying paradigm(s) of design science.

An analysis of the set of application papers, on the other hand, shows a very different set of themes within the research (see Figure 13.4). Within this set of papers there are a number of very strong recurring themes emerging, viz.design, process, data, knowledge and information. The strength of the 'design' theme is perhaps not surprising, since the majority of papers develop some type of artefact. The 'information' theme suggests a focus on information management and requirements elicitation, which is closely related to the IS implementation concept. A surprising theme is that of 'process', with a strong concept of 'business processes', 'model' and 'management' within it. This theme indicates 
that a significant proportion of papers concentrates on the application of design science in the area of process modelling, analysis and design of process-aware information systems, and business process management in general. A similar situation was found for the research domains concerning 'data' and 'knowledge', indicating that a large number of research efforts were dedicated to contributing designs in the form of data management or knowledge management systems and/or services.

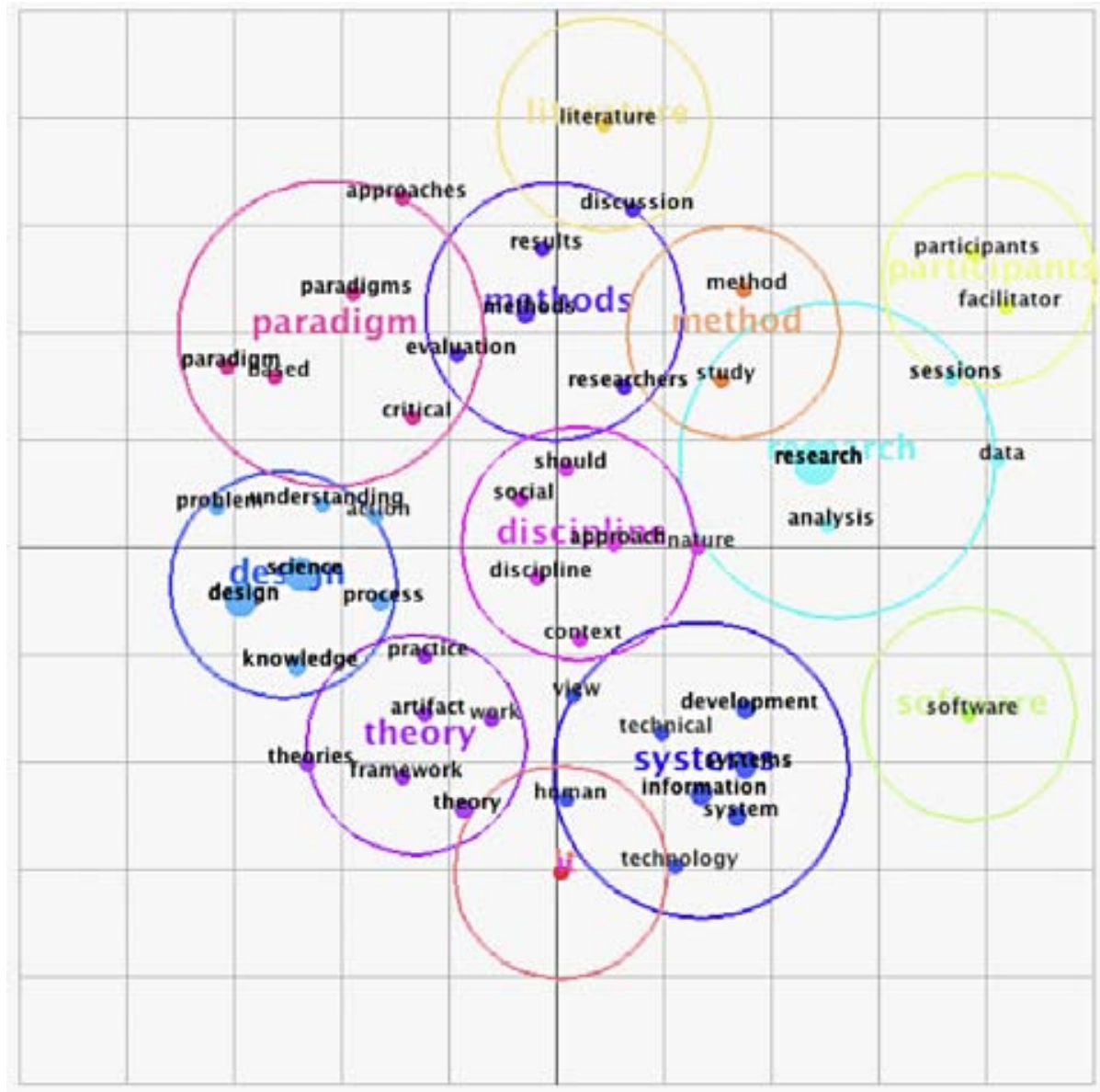

Figure 13.3 Themes identified in methodology and discussion papers 


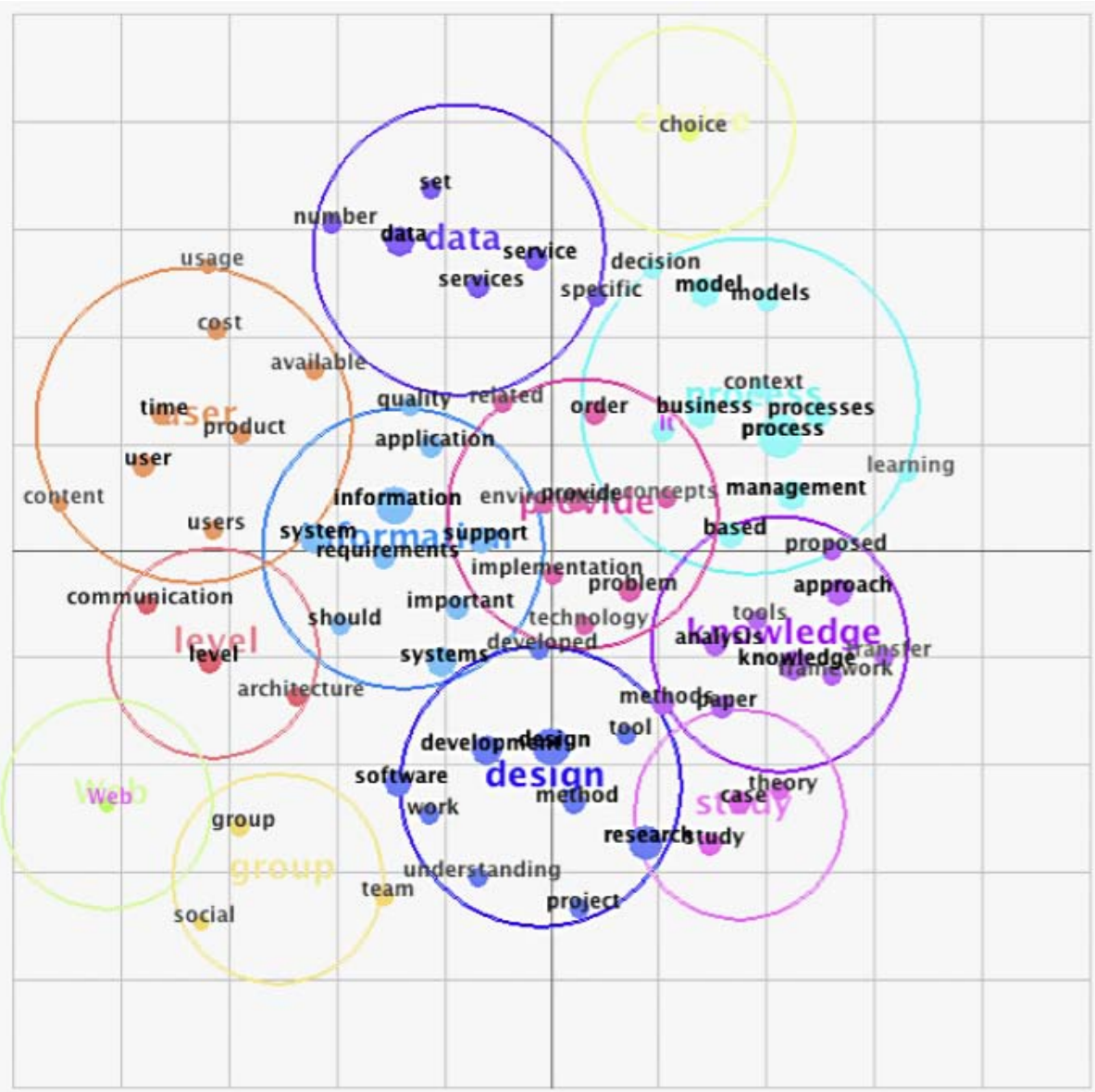

Figure 13.4 Themes identified in application papers

As a last step, to complement our methodological analysis (see section four), we conducted a seeded analysis of the application papers, looking for concepts that could be associated with the seven guidelines of design science suggested by Hevner et al. (2004). Two researchers individually analysed the automatically generated list of most frequently occurring concepts within the application paper set. From this list, a set of concepts was selected that we considered to be related to the design-science guidelines. The list of concepts was then used for the analysis of the 'application' data set, with automatic concept generation disabled. In other words, instead of using Leximancer's set of automatically generated concepts, we seeded the analysis with a smaller set of concepts that was identified by the two researchers to be of relevance to any of the seven guidelines. This seeded analysis provided an insight into the design-science guidelines that are commonly discussed within the application papers. Figure 13.5 shows the theme map generated from this analysis. 
Figure 13.5 suggests that the main emphasis of the design-science application papers is on the guidelines of development and evaluation - a finding that supports our methodological analysis presented in section four. Evaluation in particular is often empirical in nature - testing as one approach denotes a central concept in its own right. The themes of 'design' and 'evaluation' include the guidelines set out by Hevner et al. (2004) as strong concepts, indicating the centrality of these guidelines for design science conducted in IS. The analysis also shows, to a lesser extent, the feature of other guidelines in the paper set, including the communication of results and the issue of utility and relevance of the artefact. The non-centrality of these concepts could be seen as an indication that more guidance is required for IS scholars on how to address concepts of communication, relevance or utility.

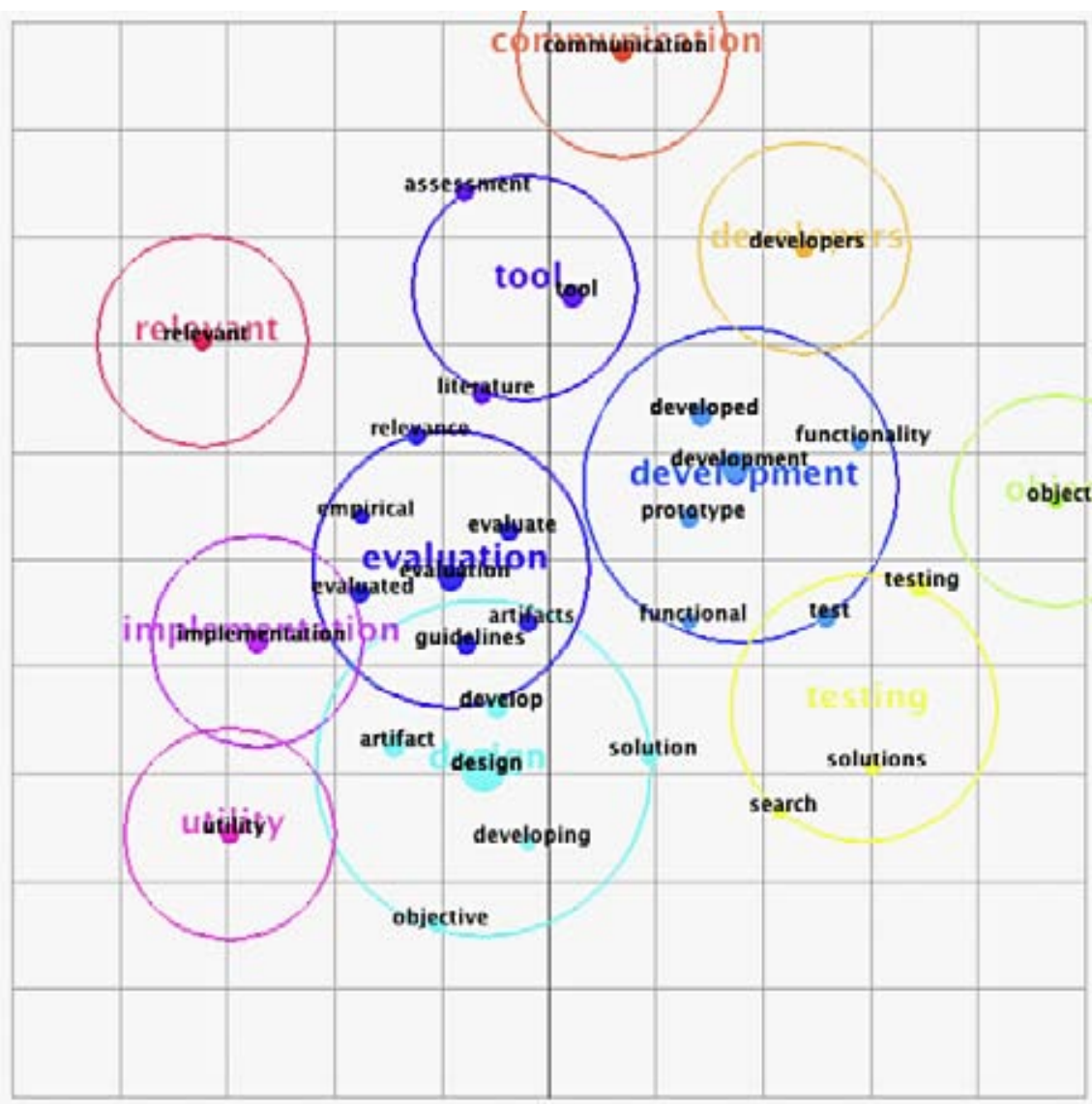

Figure 13.5 Themes related to design science guidelines in application papers 


\section{Discussion and conclusions}

In this chapter, we present an analysis of design-science publications at five prominent IS conferences - namely, ACIS, AMCIS, ECIS, ICIS and PACIS - in the period 2005-07. Our analysis is motivated by a perceived increase in designscience research in IS and the continuing discussion within the IS research community on the appropriateness, methodology and scope of design science. We use the set of published papers at these conferences as our data set and narrow it down to a set of papers that is relevant to the design-science theme, using the Hevner et al. (2004) article as a reference benchmark for our selection. We then subject the papers to a statistical, methodological and thematic analysis.

Our findings provide a number of interesting insights. First, we identify a statistically significant increase in design-science papers in the period 200507. Our findings also indicate that the majority of design-science research originates from schools in the United States (39.76 per cent). European researchers, however, appear to have an over-proportional share of designscience contributions (33.73 per cent). Second, we find that the methodological guidelines suggested by Hevner et al. (2004) have had limited overall impact on how published design-science work has been carried out to date. Only 19.3 per cent of all papers elaborate on their consideration of the Hevner et al. guidelines. We argue that this finding indicates a need for further guidance on the conduct of design-science research. To that end, we agree with McKay and Marshall (2005:7) that the original guidelines require further details on operationalisation and instantiation so that they can be of more help to designscience efforts. We also argue that a number of design-science efforts in IS fail to attain strong methodological rigour, which calls for more contributions in this area to rectify this lack. Third, our thematic analysis indicates that design science is prominent in certain domains of IS research, such as process modelling, knowledge management and tool design.

While all care has been taken to design a methodology that increased the rigour and objectivity of this study, we identify the search terms and the methodological analysis as sources of limitation of our work. In the analysis, we considered only papers that used the term 'Hevner' and/or 'design science'. This means that papers that do design science without referencing the seminal work or without identifying the work as design science are not considered in this study. At IS conferences, however, authors generally elaborate on the employed methodology. Accordingly, we consider the percentage of such potentially omitted papers to be small. In our future work, we intend to widen the scope of our analysis by including other search terms, such as 'design theory'. In a related manner, our methodological analysis was based on the authors' description within the 
chapter. Accordingly, if a guideline (for example, evaluation) was not articulated or was not implied in the paper then it was assumed it had not been followed in the published research.

Regarding methodological contributions to design science, we suggest as a step forward works such as Gregor and Jones's (2007) research on the anatomy of design theory in which they identify six core and two additional components for design theory work, or the work by Niehaves (2007), who shows how the seven guidelines could, in theory, be executed following an interpretative epistemology. In light of the recent emergence of methodological contributions to design science, we can put forward the hope that we will see an increase in methodologically sound, theoretically strong and methodically well-executed design-science contributions to IS research in the future.

\section{References}

Applegate, L. and King, J. L. 1999, 'Rigor and relevance: careers on the line', MIS Quarterly, vol. 23, no. 1, pp. 17-18.

Benbasat, I. and Zmud, R. W. 1999, 'Empirical research in information systems. The practice of relevance', MIS Quarterly, vol. 23, no. 1, pp. 3-16.

Carlsson, S. A. 2005a, 'Design science research in information systems: a critical realist perspective', in B. Campbell, J. Underwood and D. Bunker (eds), Proceedings of the 16th Australasian Conference on Information Systems, Australasian Chapter of the Association for Information Systems, Sydney.

Carlsson, S. A. 2005b, 'Developing information systems design knowledge: a critical realist perspective', The Electronic Journal of Business Research Methodology, vol. 3, no. 2, pp. 93-102.

Gibson, M. and Arnott, D. 2007, 'The use of focus groups in design science research', in M. Toleman, A. Cater-Steel and D. Roberts (eds), Proceedings of the 18th Australasian Conference on Information Systems, University of Southern Queensland, Toowoomba, Qld, pp. 327-37.

Gregor, S. and Jones, D. 2007, 'The anatomy of a design theory', Journal of the Association for Information Systems, vol. 8, no. 5, pp. 312-35.

Hevner, A. R., March, S. T., Park, J. and Ram, S. 2004, 'Design science in information systems research', MIS Quarterly, vol. 28, no. 1, pp. 75-105.

Klose, K., Knackstedt, R. and Beverungen, D. 2007, 'Identification of services - a stakeholder-based approach to SOA development and its application in 
the area of production planning', in H. Österle, J. Schlep and R. Winter (eds), Proceedings of the 15th European Conference on Information Systems, University of St Gallen, Switzerland, pp. 1802-14.

Knackstedt, R., Winkelmann, A. and Becker, J. 2007, 'Dynamic alignment of ERP systems and their documentations - an approach for documentation quality improvement', Proceedings of the 13th Americas Conference on Information Systems, Association for Information Systems, Keystone, Colo.

Lyytinen, K., Baskerville, R., Iivari, J. and Te'Eni, D. 2007, 'Why the old world cannot publish? Overcoming challenges in publishing high-impact IS research', European Journal of Information Systems, vol. 16, no. 4, pp. 317-26.

McKay, J. and Marshall, P. 2005, 'A review of design science in information systems', in B. Campbell, J. Underwood and D. Bunker (eds), Proceedings of the 16th Australasian Conference on Information Systems, Australasian Chapter of the Association for Information Systems, Sydney.

March, S. T. and Smith, G. F. 1995, 'Design and natural science research on information technology', Decision Support Systems, vol. 15, no. 4, pp. 25166.

Markus, M. L., Majchrzak, A. and Gasser, L. 2002, 'A design theory for systems that support emergent knowledge processes', MIS Quarterly, vol. 26, no. 3, pp. 179-212.

Niehaves, B. 2007, 'On epistemological diversity in design science: new vistas for a design-oriented IS research?', Proceedings of the 28th International Conference on Information Systems, Association for Information Systems, Montreal.

Purao, S., Sein, M. K., Rossi, M. and Cole, R. 2005, 'Being proactive: where action research meets design research', in D. E. Avison and D. F. Galletta (eds), Proceedings of the 26th International Conference on Information Systems, Association for Information Systems, Las Vegas, Nev.

Rosemann, M. and Vessey, I. 2008, 'Toward improving the relevance of IS research to practice: the role of applicability checks', MIS Quarterly, vol. 32, no. 1, pp. 1-22.

Tan, X., Siau, K. and Erickson, J. 2007, 'Design science research on systems analysis and design: the case of UML', Proceedings of the 13th Americas Conference on Information Systems, Association for Information Systems, Keystone, Colo. 
Walls, J. G., Widmeyer, G. R. and El Sawy, O. A. 1992, 'Building an information systems design theory for vigilant EIS', Information Systems Research, vol. 3, no. 1, pp. 36-59.

Zmud, R. W. and Boynton, A. C. 1991, 'Survey measures and instruments in MIS: inventory and appraisal', in K. L. Kraemer (ed.), The Information Systems Research Challenge: Survey research methods, Harvard Business School, Boston, Mass., pp. 149-80. 